\title{
EDUCAÇÃO E POLÍTICA EM THEODOR ADORNO: PARA ONDE A EDUCAÇÃO DEVE CONDUZIR?
}

\author{
Education and politics in Theodor Adorno: where education should lead?
}

Luana Aparecida de Oliveira *

Resumo: A partir das contribuições filosóficas da Teoria Crítica de Theodor W. Adorno para o debate político-educacional, pretendemos problematizar o modelo ideológico da semiformação instituída que embasa o sistema de ensino vigente, este que por meio de suas práticas reforça os valores egoístas, competitivos e consumistas próprios da sociedade em que reina o capitalismo tardio. Nesse sentido é importante que se faça a pergunta: para onde a educação deve conduzir o sujeito? Para este fim, nosso objetivo é fazer o confronto crítico desta educação que propaga a semiformação, com a proposta adorniana de uma educação comprometida com a formação emancipatória do sujeito. Em meio a esta temática serão abordados os principais conceitos da filosofia de Adorno de modo a esclarecer os elementos que os constituem, articulando sua relação com a educação e seu caráter político, sendo eles: razão instrumental, não-idêntico, experiência formativa, semiformação, barbárie, indústria cultural, resistência, adaptação e emancipação. Também será exposto o caráter ambíguo da educação, ela que se apresenta simultaneamente como adaptação e como resistência. No entanto, defenderemos que em tempos de conformação cega com o status quo, torna-se necessário que a educação se volte para a primazia (provisória) da resistência, de modo à refortalecer o potencial de auto-reflexão crítica, e, por conseguinte, de contestação do sujeito frente à sua adaptação à ordem social vigente.

Palavras-chave: educação, emancipação, adaptação,

\begin{abstract}
From the philosophical contributions of the Critical Theory of Theodor W. Adorno for political and educational debate, we intend to problematize the ideological model of established semiformation that supports the system of education present, this that through their practices reinforces the selfish values, competitive and consumerists own of society in which reigns the late capitalism. In this sense it is important to ask the question: where education should lead the subject? To this end, we aim to do the critical confrontation this education that propagates the semiformation, with Adorno's proposal an education committed to an emancipatory subject formation. Amid this theme will be address the major concepts of the philosophy of Adorno to clarify the elements that constitute the articulation of the relationship of education to their political character, namely: instrumental reason, non-identical, experience formative, semiformation, barbarism, cultural industry, endurance, adaptation and emancipation. Also be exposed to the ambiguous character of education, she that appears as both adaptation and as resistance. However, defend that it in times of blind conformity to status quo, becomes necessary that education turns to the primacy (Provisional) resistance, in order to strengthen the potential for critical self-reflection, and therefore, subject to front of the adaptation challenge the existing social order.
\end{abstract}

Keywords: Education, emancipation, adaptation, resistance

* Mestranda em Filosofia pela Universidade Estadual do Oeste do Paraná (UNIOESTE) - luanatuba@ hotmail.com

\begin{tabular}{|c|c|c|c|c|c|}
\hline intuitio & $\begin{array}{c}\text { ISSN } \\
1983-4012 \\
\end{array}$ & Porto Alegre & Vol.8 - $\mathrm{N}^{\mathrm{o}} .1$ & $\begin{array}{l}\text { Junho } \\
2015 \\
\end{array}$ & p.64-74 \\
\hline
\end{tabular}


Educação e política em Theodor Adorno: para onde a educação deve conduzir?

Conforme a obra intitulada Educação e Emancipação de Theodor W. Adorno, a educação não está relacionada à modelagem de pessoas, tão pouco à simples transmissão de conhecimentos. Educação em Adorno está vinculada com o esclarecimento, com a formação de uma consciência verdadeira, ou seja, com a busca pela autonomia, pela emancipação:

[...] concebo como sendo educação [...] não a assim chamada modelagem de seres humanos, porque não temos direito algum de modelar pessoas a partir do exterior, mas também não a mera transmissão de saber, cuja característica de coisa morta já foi mais do que destacada, e sim a produção de uma consciência verdadeira. Esta teria grande significado político; podemos dizer que sua idéia é politicamente impositiva. Isto é, uma democracia com o dever de não apenas funcionar, mas operar conforme seu conceito, demanda pessoas emancipadas. Uma democracia efetiva só pode ser imaginada enquanto uma sociedade de quem é emancipado ${ }^{1}$.

Portanto, a reflexão educacional que se faz a partir das obras de Adorno abre possibilidade para um enfoque político, já que a emancipação é uma exigência política e confere à educação ter ela como objetivo, em outras palavras, o sentido político da educação está relacionado com o seu comprometimento com o desenvolvimento de uma consciência emancipada. Porém, a escola enquanto instituição social pertencente à sociedade em que reina o capitalismo tardio ${ }^{2}$ propaga o modelo ideológico da semiformação, a qual não viabiliza os pressupostos necessários para a condição emancipatória. No ensaio Teoria da semicultura Adorno esclarece que o conceito de semiformação trata-se da "[...] forma dominante da consciência atual [...]”3, a formação cultural está em colapso e por isso cede lugar à semiformação socializada, estado onde a alienação é onipresente. É importante destacar um equívoco comum que ocorre na busca ao entendimento sobre a semiformação: ela não é parte do percurso que se direciona rumo à formação, ela não antecede a formação cultural, mas sim a inviabiliza na medida em que deforma o sujeito, seja por que o adapta totalmente ao mundo, seja porque o insere em uma concepção e cultura totalmente exterior à realidade social e histórica. Ambas bloqueiam a capacidade crítica e autônoma do sujeito. Embora Adorno tenha escrito sobre a crise da formação em 1960 podemos dizer que sua análise continua atual, pois a formação que se absolutiza se converte em semiformação, e assim deixa de ser formação, independente da época:

Quando o campo de forças a que chamamos formação se congela em categorias fixas - sejam elas do espírito ou da natureza, de transcendência ou de

\footnotetext{
${ }^{1}$ ADORNO, Theodor W. Educação e Emancipação. Tradução: Wolfgang Leo Maar. Rio de Janeiro: Paz e Terra, 1995. p. 141-142.

2 O termo capitalismo tardio refere-se ao capitalismo que poderia ter sido superado, mas não foi, se mantém tardiamente.

${ }^{3}$ ADORNO, Theodor W. Teoria da Semicultura. In: Educação e sociedade n. 56. Tradução Bruno Pucci, Cláudia B. M. de Abreu e Newton Ramos-de-Oliveira. 1996. p. 389.
}

\begin{tabular}{|c|c|l|l|l|l|}
\hline intuitio & $\begin{array}{c}\text { ISSN } \\
1983-4012\end{array}$ & Porto Alegre & Vol.8 $-\mathrm{N}^{\circ} .1$ & $\begin{array}{c}\text { Junho } \\
2015\end{array}$ & p.64-74 \\
\hline
\end{tabular}


Educação e política em Theodor Adorno: para onde a educação deve conduzir?

acomodação - cada uma delas, isolada, se coloca em contradição com seu sentido, fortalece a ideologia e promove uma formação regressiva ${ }^{4}$.

Para o senso comum a cultura é sagrada, no entanto, Adorno afirma que esta perspectiva também reforça a semiformação, pois deturpa o sentido de formação na medida em que elimina a tensão necessária. Foi com o desenvolvimento da burguesia alemã que a formação adquiriu sua forma cultural, o conceito carregava o desejo de seres livres e iguais e era, mesmo que implícita, uma exigência prévia para que a sociedade fosse autônoma. No entanto, contraditoriamente a relação com a prática ocorreu de forma diferente, pois na barbárie capitalista a formação cultural tornou-se, na verdade, privilégio de poucos:

Sem dúvida, na ideia de formação cultural necessariamente se postula a situação de uma humanidade sem status e sem exploração [...] Os dominantes monopolizaram a formação cultural numa sociedade formalmente vazia. A desumanização implantada pelo processo capitalista de produção negou aos trabalhadores todos os pressupostos para a formação e, acima de tudo, o ócio ${ }^{5}$.

Ainda em seu ensaio, Adorno traz o exemplo do mecânico que é julgado como inculto segundo os critérios da ideia burguesa de formação, sendo desconsiderado que para exercer sua profissão terá que possuir muitos conhecimentos. O desenvolvimento do capitalismo trouxe elementos que contribuem para que a formação se converta em semiformação, a saber, o progresso das técnicas e a racionalidade instrumental, esta última trataremos mais a frente. Na filosofia adorniana há dois elementos que constituem o sentido de formação, a autonomia/resistência e a adaptação, desta forma, há uma constante tensão, ora num momento, ora em outro conforme explica Pucci:

É a tensão entre esses dois momentos, do espírito e da integração, da autonomia e da adaptação, que constitui o conceito de formação; o homem deve ser um cidadão de seu tempo, integrando-se no conhecimento e no desenvolvimento das potencialidades humanas, utilizando-se das tecnologias mais avançadas que a situação histórica lhe apresenta; mas ao mesmo tempo, tem de ser crítico de seus dias, problematizar-lhes as injustiças existentes, não deixar-se dominar pelo coletivo ${ }^{6}$.

Dado que o conceito de formação possui duplo sentido e é a tensão entre um momento e outro que o constitui enquanto tal, quando um momento domina o outro e acaba com a tensão necessária, ocorre então o predomínio da consciência alienada e do conformismo cego, é aí que reside o potencial destrutivo da semiformação. Portanto, a formação não pode ser entendida enquanto pura conformação à vida, caso assim for, ela se petrificará no momento da adaptação e se transformará em semiformação. Por outro lado,

\footnotetext{
${ }^{4}$ ADORNO, Theodor W. Teoria da Semicultura. In: Educação e sociedade n. 56. Tradução Bruno Pucci, Cláudia B. M. de Abreu e Newton Ramos-de-Oliveira. 1996. p. 390.

${ }^{5}$ ADORNO, Theodor W. Teoria da Semicultura. In: Educação e sociedade n. 56. Tradução Bruno Pucci, Cláudia B. M. de Abreu e Newton Ramos-de-Oliveira. 1996. p. 391.

6 PUCCI, Bruno. A dialética negativa enquanto metodologia de pesquisa em educação: atualidades. Revista Ecurriculum, São Paulo, v.8 n.1 Abril 2012. p. 15.
}

\begin{tabular}{|c|c|l|l|l|l|}
\hline intuitio & $\begin{array}{c}\text { ISSN } \\
1983-4012\end{array}$ & Porto Alegre & Vol.8 $-\mathrm{N}^{\mathrm{o}} .1$ & $\begin{array}{c}\text { Junho } \\
2015\end{array}$ & p.64-74 \\
\hline
\end{tabular}


Educação e política em Theodor Adorno: para onde a educação deve conduzir?

a semiformação também ganhará espaço se ocorrer o empedramento no momento da resistência, podendo haver em decorrência uma concepção de formação elitista, fechada em si mesma, ou então desenraizada, isto é que desconsidera toda construção histórico-social pelo motivo dela ser o condicionante que influencia fortemente o ser, querendo por isso, desconstruir, boicotar e reinventar incessantemente as formas sociais vigentes, nem mesmo sendo levada em conta uma adaptação mínima e necessária para a própria sobrevivência. Pucci nos traz outro exemplo a respeito da fetichização no momento adaptativo:

Adorno observa que nas configurações históricas, a polaridade, de fato, nunca se deu de forma satisfatória; no modelo liberal, por exemplo, se enfatizou a autonomia em detrimento da adaptação, e isso apenas entre alguns setores privilegiados - intelectuais, artistas, políticos, dirigentes - sob o preço da exclusão dos trabalhadores da formação cultural ${ }^{7}$.

Deste modo, quando um dos momentos é fetichizado, seja o da adaptação ou da autonomia/resistência, a semiformação se instaura. Sendo esta a deformação da própria formação, é uma barreira à formação, a qual provoca uma falsa consciência, não se limitando apenas ao aspecto intelectual, mas se ampliando também para o empobrecimento geral do ser humano, em todas as suas formas de ser. A partir desta exposição sobre a problemática da semiformação na filosofia adorniana, podemos pensar sua relação com o sistema de ensino: não raras vezes ele se torna uma das agências que reforça a semiformação já instaurada na sociedade. Mas se a educação legitima ou mesmo se torna a própria semiformação, como ela irá promover situações favoráveis ao desenvolvimento de uma consciência verdadeira, uma consciência emancipada capaz de refletir criticamente acerca das contradições e imposições sociais existentes? Para Adorno, a semiformação traz substâncias tóxicas à faculdade do pensar por meio do conhecimento que não é assimilado, coisificando assim, a consciência tal como na anedota do toneleiro que:

[...] em seu desejo por algo mais elevado, se dedicou à Crítica da razão pura e acabou na astrologia, evidentemente porque apenas nela seria possível unificar $a$ lei moral que existe em nós com o céu estrelado que está sobre nós. Elementos formativos inassimilados fortalecem a reificação da consciência que deveria justamente ser extirpada pela formação ${ }^{8}$.

O sistema educacional não é neutro, está mergulhado na lógica do status quo e, em grande medida, visa assegurar a continuidade desta lógica de modo que suas práticas pedagógicas direcionem-se à adaptação da condição social vigente. Porém, voltado somente para o momento adaptativo, onde muitas vezes se engessa, não consegue realizar o objetivo da emancipação. Por isso a semiformação instituída,

7 PUCCI, Bruno. “Anotações sobre teoria e práxis educativa”. Disponível em: <<http://www.unimep.br/ bpucci/anotacoes-teoria-praxis.pdf. >> Acessado em: 16 de maio de 2014.

${ }^{8}$ ADORNO, Theodor W. Teoria da Semicultura. In: Educação e sociedade n. 56. Tradução Bruno Pucci, Cláudia B. M. de Abreu e Newton Ramos-de-Oliveira. 1996. p. 389.

\begin{tabular}{|c|c|c|c|c|c|}
\hline intuitio & $\begin{array}{c}\text { ISSN } \\
1983-4012\end{array}$ & Porto Alegre & Vol.8 $-\mathrm{N}^{\circ} .1$ & $\begin{array}{c}\text { Junho } \\
2015\end{array}$ & p.64-74 \\
\hline
\end{tabular}


Educação e política em Theodor Adorno: para onde a educação deve conduzir?

que embasa a maior parte do sistema de ensino, confronta com a proposta adorniana de uma educação comprometida com a tarefa social de denunciar a falsa consciência e de promover a autonomia do sujeito por meio da formação emancipatória. A proposta política da educação propulsora da emancipação tem como propósito tornar explícitas as contradições existentes e fomentar a resistência contra estas mediante a reflexão crítica.

Assim como a educação tem a função política de problematizar e de não aceitar como válidos os valores egoístas, competitivos e consumistas, próprios da sociedade onde o capitalismo tardio se faz presente, ela também não deve ser um instrumento para a cidadania enquanto distante da realidade histórica e social, no sentido de oferecer conhecimentos e valores definitivos para orientar a conduta dos indivíduos no transcurso de sua trajetória. Para Adorno cabe à educação auxiliar na formação de uma consciência verdadeira, autônoma, não apenas enquanto faculdade de um pensar lógico e formal, mas também enquanto interação com a realidade e com o não idêntico que esta mesma realidade reprime, para a partir daí haver a experiência formativa. Em última instância, a consciência autônoma se funda na capacidade dos indivíduos fazer experiências e esta por sua vez relaciona-se com a emancipação:

Mas aquilo que caracteriza propriamente a consciência é o pensar em relação à realidade, ao conteúdo - a relação entre as formas e estruturas do pensamento do sujeito e aquilo que este não é. Este sentido mais profundo de consciência ou faculdade de pensar não é apenas o desenvolvimento lógico formal, mas ele corresponde literalmente à capacidade de fazer experiências. Eu diria que pensar é o mesmo que fazer experiências intelectuais. Nesta medida e nos termos que procuramos expor, a educação para a experiência é idêntica à educação para a emancipação ${ }^{9}$.

O conceito de experiência formativa se refere a um processo dialético e também auto reflexivo, onde o sujeito torna-se o que é a partir da relação com aquilo que ele não é, ocorrendo sua transformação mediante o contato produtivo com o objeto. A consciência autônoma também está vinculada como a conscientização dos elementos que castram a experiência, um destes elementos diz respeito à repressão do não-idêntico que se opõe à experiência formativa em defesa de uma sociedade homogênea. $\mathrm{O}$ nãoidêntico, aquilo que não é tematizado, revela-se como possibilidade de mudança, desta forma, deixar-se afetar pelo não-idêntico, ou então experienciar o não-idêntico, já que ele revela-se enquanto permissão da tematização do diferente, é resistir ao princípio da identidade, e é também condição de possibilidade da educação.

Sobre o não-idêntico, Adorno afirma que a filosofia idealista de Hegel se equivoca ao ser fundada no princípio da identidade em que o conhecimento no âmbito da razão expressa a correspondência entre ser e pensar, trazendo o pressuposto de que os conceitos representam o real enquanto tal. Para Adorno os

${ }^{9}$ ADORNO, Theodor W. Educação e Emancipação. Tradução: Wolfgang Leo Maar. Rio de Janeiro: Paz e Terra, 1995. p.151.

\begin{tabular}{|c|c|l|l|l|l|}
\hline intuitio & $\begin{array}{c}\text { ISSN } \\
1983-4012\end{array}$ & Porto Alegre & Vol.8 $-\mathrm{N}^{\circ} .1$ & $\begin{array}{c}\text { Junho } \\
2015\end{array}$ & p.64-74 \\
\hline
\end{tabular}


Educação e política em Theodor Adorno: para onde a educação deve conduzir?

conceitos não traduzem a coisa em si em sua plenitude, já que o conteúdo da coisa em si traz também o não idêntico a si mesmo: “[...] o não-idêntico seria a identidade própria da coisa contra suas identificações" ${ }^{\prime 10}$. Assim, considerando que os conceitos não relatam a totalidade da realidade, pois não abarcam o não idêntico, pode-se dizer que há uma tensão entre pensamento e objeto, a qual impossibilita a exatidão da equiparação entre os mesmo. Portanto, o pensamento não representa fielmente o objeto, pois não dá conta de teorizar o que não pode ser conceitualizado.

Ao contrário de Hegel que atribuía primazia ao sujeito cognoscente e que pressupõe alcançar a verdade através de uma elaboração linear de argumentos, a primazia do objeto é o motor da dialética negativa de Adorno. Esta reconhece a impossibilidade de se chegar à verdade absoluta, mas isso também não significa que a verdade se encontra no objeto. A dialética negativa não tem como pretensão o endeusamento de uma verdade, e por isso acaba impedindo ações autoritárias. Um conceito isolado não representa fielmente o objeto, no entanto, se aliado a outros conceitos, de modo a formar uma constelação, torna-se então mais próximo da verdade. Porém, como já é suposto, de forma alguma essa constelação conceitual pretende absolutizar uma verdade, pois esta constelação não carrega consigo a estaticidade, a fixidez e a imutabilidade, e sim uma constante transformação na qual os conceitos estão interligados, isto é, relacionados entre si em um movimento dinâmico, num processo em devir. Assim, cada conceito é um fragmento que irá compor uma verdade e que juntos iluminam a compreensão da realidade, esta que pelo fato de ser histórica também é dinâmica.

A primazia do objeto instiga o sujeito a refletir sobre aquilo que não é apreendido conceitualmente, pois mesmo sabendo que não poderá absolutizar uma verdade há a tentativa do pensamento se aproximar cada vez mais dela por meio da ampliação da constelação conceitual, desta forma, ocorre uma reflexão contínua sobre o próprio pensar, uma auto reflexão da razão. Esta não acomodação do pensamento leva à persistência do pensamento crítico, sendo este condição de possibilidade para a autonomia do sujeito. É importante destacar que para Adorno, embora haja a primazia do objeto, o sujeito não é colocado de lado, sua importância ainda é reconhecida. Acontece que nesta relação o sujeito tem consciência de sua limitação, sabe que não é capaz de dominar por completo o objeto por não ter acesso direto a ele, por isso a auto-reflexão sobre o não idêntico não se torna estática, está sim em constante movimento.

A exclusão do não-idêntico em privilégio do sempre igual gera um obstáculo à experiência formativa do sujeito, sendo este o fenômeno da semiformação. Além do sistema educacional outro disseminador da semiformação é a indústria cultural, termo criado por Adorno e Max Horkheimer que se

\footnotetext{
${ }^{10}$ ADORNO apud DUARTE, Rodrigo Antônio de Paiva. Mímesis e racionalidade: a concepção de domínio da natureza em Theodor W. Adorno. São Paulo: Loyola, 1993. p. 67.
}

\begin{tabular}{|c|c|c|c|c|c|}
\hline intuitio & $\begin{array}{c}\text { ISSN } \\
1983-4012\end{array}$ & Porto Alegre & Vol.8 $-\mathrm{N}^{\mathrm{o}} .1$ & $\begin{array}{c}\text { Junho } \\
2015\end{array}$ & p.64-74 \\
\hline
\end{tabular}


Educação e política em Theodor Adorno: para onde a educação deve conduzir?

refere à reificação da cultura, isto é, à produção de uma cultura adaptada para o consumo em massa, desprovida de valor crítico e carregada de ideologia comercial. Essa cultura fraudada é produzida em moldes padronizados e ofertada como sendo objeto de mercadoria e, assim, a máquina capitalista aniquila com o seu caráter crítico.

Conforme Adorno "[...] a Indústria Cultural impede a formação de indivíduos autônomos, independentes, capazes de julgar e de decidir conscientemente." ${ }^{\prime 1}$. Desta forma, considerando que a indústria cultural age com o objetivo de servir interesses político-econômicos, embutindo de maneira apelativa (supostas) necessidades de consumo, é pressuposto que ela tende a enfraquecer as possibilidades de uma postura crítica, sem a qual não há a contestação do status quo. É por isso, portanto, que o objetivo político-pedagógico da educação comprometida com a formação emancipatória, necessita se voltar para a reflexão acerca dos mecanismos que ameaçam e que até mesmo impedem a emancipação dos indivíduos. Também fica evidente a importância da educação priorizar a auto-reflexão crítica já que ela é elemento fundamental no processo de superação indústria cultural:

A auto-reflexão crítica para os frankfurtianos representa um elemento fundamental na luta pela emancipação. Por ela os dominados podem ser esclarecidos a respeito de sua situação enquanto classe, no contexto de exploração e subordinação capitalista. [...] Serviria para orientá-los à conseqüente ação transformadora que a própria ação transformadora exige. Ela se torna educativa em dois sentidos; no esclarecimento dos mecanismos de alienação e de manipulação ideológica presentes no sistema, e na revelação de verdades não intencionais que poderiam conter 'imagens fugidias' de uma sociedade diferente ${ }^{12}$.

Segundo Pucci, para haver ações transformadoras é necessário tomar uma postura crítica de modo a apontar para a superação das contradições sócio-históricas desta sociedade, na qual a própria ordem é fundada ideologicamente, não bastando apenas tomar consciência dos elementos de dominação através da descrição dos pressupostos e das contradições estruturantes da sociedade capitalista. Em relação à postura crítica, outro obstáculo à formação emancipadora é a razão instrumental que é incapaz de um olhar crítico a respeito de seus próprios fins, assim como de se questionar a serviço de quem e de quê ela está. Para Adorno a razão, assim como a formação não exige só a negação, só a resistência e inadequação frente à realidade, a razão também precisa ser adaptação, tendo o devido cuidado para este ser apenas um momento e não se tornar constante. A razão está sempre na tensão dinâmica a qual confronta com a realidade, mas que também se adéqua a ela, conforme explica Leo Maar:

\footnotetext{
${ }^{11}$ ADORNO,Theodor W. Conceito de Iluminismo. In: Os Pensadores. Textos escolhidos. Tradução: Luiz João Baraúna. São Paulo: Nova Cultural, 1999. p. 109.

${ }^{12}$ PUCCI, Bruno. Teoria Crítica e Educação. In: PUCCI, Bruno (org.). Teoria Crítica e Educação: a questão da formação cultural na escola de Frankfurt. Petrópolis: Vozes, 1995. p. 48.
}

\begin{tabular}{|c|c|l|l|l|l|}
\hline intuitio & $\begin{array}{c}\text { ISSN } \\
1983-4012\end{array}$ & Porto Alegre & Vol.8 $-\mathrm{N}^{\mathrm{o} .1}$ & $\begin{array}{c}\text { Junho } \\
2015\end{array}$ & p.64-74 \\
\hline
\end{tabular}


Educação e política em Theodor Adorno: para onde a educação deve conduzir?

[...] pela necessidade de se adaptar, e pela necessidade de não se limitar à adaptação, mas recorrer à resistência contra o que a adaptação significa em termos de imposição da realidade com algo meramente "exterior", não apreendida numa relação de "experiência" para o sujeito como "realidade não verdadeiramente racional" 13 .

No entanto, a razão que se fixa no momento adaptativo deixa de ser razão esclarecida e se transforma em razão instrumental, sendo a racionalidade reduzida à "capacidade" de se adaptar bem à realidade tal como ela é, o que na verdade é um condicionamento social que força a adaptação àquilo que já é estabelecido como natural, conforme explicita Adorno: “[...] as pessoas aceitam com menor ou maior resistência aquilo que a existência dominante apresenta a sua vista e ainda por cima lhes inculca à força como se aquilo que existe precisasse existir dessa forma"14.

A sociedade que permanece na racionalidade instrumental não percebe que o desenvolvimento científico, embora tenha potencial para auxiliar no projeto de uma sociedade emancipada, não leva necessariamente à emancipação do sujeito. E por não perceber isto, não submete à dúvida a afirmação de que vivemos em uma sociedade esclarecida. Enquanto esta venda persistir a racionalidade instrumental continuará contribuindo com o poder ideológico da indústria cultural e com as contradições sociais que geram a semiformação. Desta forma, cabe ao sistema educacional o compromisso social de denunciar esta falsa consciência que é propagada diariamente e que promove conformismo e submissão frente à lógica do status quo.

Conforme já foi abordado, a formação é adaptação porque ela nos dá preparo para vivermos em sociedade, nos repassando conhecimentos e toda bagagem cultural por meio do processo de ensinoaprendizagem:

A educação seria impotente e ideológica se ignorasse esta finalidade de adaptação, e não preparasse os homens a operarem na realidade. Mas ela seria igualmente questionável se se reduzisse a isto, produzindo nada mais do que "well adjusted people". Nesta medida, no conceito de educar para tornar racional e para tornar consciente existe de antemão uma cisão, uma ambiguidade ${ }^{15}$.

Mas se deter no momento adaptativo é padronizar comportamentos, de modo a haver uma progressiva perda da individualidade, de tal forma que ninguém conseguirá viver a seu próprio modo, além de haver a tendência à absorsão e à conformação cega do já estabelecido, resultando num comportamento passivo e omisso, como por exemplo, diante da própria barbárie. Por isso a educação que

\footnotetext{
${ }^{13}$ MAAR, Wolfgang Leo. Educação Crítica, Formação Cultural e Emancipação Política na Escola de Frankfurt. In: PUCCI, Bruno (org.). Teoria Crítica e Educação: A questão da formação cultural na escola de Frankfurt. Petrópolis: Vozes, 1995. p. 63.

${ }^{14}$ ADORNO, Theodor W. Educação e Emancipação. Tradução: Wolfgang Leo Maar. Rio de Janeiro: Paz e Terra, 1995. p.178.

${ }^{15}$ ADORNO, Theodor W. Educação e Emancipação. Tradução: Wolfgang Leo Maar. Rio de Janeiro: Paz e Terra, 1995. p. 143.
}

\begin{tabular}{|c|c|c|c|c|c|}
\hline intuitio & $\begin{array}{c}\text { ISSN } \\
1983-4012\end{array}$ & Porto Alegre & Vol.8 $-\mathrm{N}^{\circ} .1$ & $\begin{array}{c}\text { Junho } \\
2015\end{array}$ & p.64-74 \\
\hline
\end{tabular}


Educação e política em Theodor Adorno: para onde a educação deve conduzir?

se volta para o objetivo da emancipação necessita ser ambas: adaptação e resistência. No entanto, considerando o contexto em que vivemos, destaco a importância da ação educativa se voltar mais à resistência, de modo a promover espaços favoráveis à reflexão crítica, pois conforme Zuin:

Ocorre que, atualmente, que o exercício da reflexão crítica encontra-se cada vez mais impossibilitado de ser concretizado, uma vez que as maiores recompensas são entregues para aqueles que melhor se "adaptam" - leia-se integram-se - ao sistema, nas suas mais variadas instâncias, inclusive na própria escola ${ }^{16}$

A existência dominante desde sedo já nos coloca num processo automático de adaptação do sempre idêntico, dizendo previamente com o que devemos ou não nos habituar, com exigências onde o não-idêntico perde sua vez. Quando a educação se petrifica no momento adaptativo não se pode considerá-la emancipadora, pois neste caso ela carrega consigo a tendência ao totalitarismo e ao resurgimento da barbárie, visto que age de modo a converter os indivíduos em sujeitos possuidores de consciência ingênua, capazes de se omitirem e de se resignarem frente às situações decisivas. Portanto, a educação que prioriza a resistência está também comprometida em orientar os indivíduos contra a barbárie. Há de se considerar ainda que superar ou não a barbárie é uma questão que envolve a própria sobrevivência da humanidade, por isso Adorno afirma que "[...] desbarbarizar tornou-se a questão mais urgente da educação hoje em dia" ${ }^{17}$.

Para o autor, a barbárie ainda permanece presente na conduta humana devido o passado mal elaborado. Sua elaboração trata-se de dar sentido à história, reelaborando sua relação com o presente. A elaboração também pode ser entendida como esclarecimento do passado, num processo de reconhecimento e identificação das causas, que levaram, como por exemplo, à violência que ocorreu em Auschwitz, para que a partir desta reflexão eliminem-se essas causas, e para que assim as barbáries já cometidas não se repitam mais. É importante obter conhecimento referente aos mecanismos que tornam os homens reféns da barbárie, sendo necessário entender como que a conduta agressiva se constitui, e apurar os motivos que levam aos atos de extrema violência, não para justificar tais atos, mas com o propósito de evitar a formação dessa conduta.

Neste sentido, é relevante salientar que a educação voltada somente para a adaptação possui elementos de barbárie que se expressam em momentos de repressão e opressão, temos como exemplo as formas autoritárias dos professores agirem em sala de aula, visto que muitos ainda ensinam por meio do medo. Deste modo, o sistema educacional pode ser agente propagador da razão que desumaniza, contribuindo com as injustiças sociais ao reproduzir normas e valores da ideologia da semicultura. Mas

${ }^{16}$ ZUIN, Antônio Álvaro Soares. Seduções e Simulacros: considerações sobre a indústria cultural e os paradigmas da resistência e da reprodução em educação. In: PUCCI, Bruno (org.). Teoria Crítica e Educação: A questão da formação na escola de Frankfurt. Petrópolis: Vozes, 1995. p.167-168.

${ }_{17}$ ADORNO, Theodor W. Educação e Emancipação. Tradução: Wolfgang Leo Maar. Rio de Janeiro: Paz e Terra, 1995. p.155.

\begin{tabular}{|c|c|l|l|l|l|}
\hline intuitio & $\begin{array}{c}\text { ISSN } \\
1983-4012\end{array}$ & Porto Alegre & Vol.8 $-\mathrm{N}^{\circ} .1$ & $\begin{array}{c}\text { Junho } \\
2015\end{array}$ & p.64-74 \\
\hline
\end{tabular}


Educação e política em Theodor Adorno: para onde a educação deve conduzir?

por outro lado, a educação também possui potencial para defender uma proposta política pedagógica que vise uma formação emancipatória, a começar pelo processo de ensino-aprendizagem fazer uso permanente de uma reflexão mais profunda acerca de como e do quê ensina, lembrando sempre de preservar a memória da experiência do nazismo para que este nunca mais se repita.

Por fim, reforço a tese da primazia da resistência no contexto atual em que o momento da adaptação está petrificado, pois considerando que o sistema educacional está inserido na sociedade dominada pelo capitalismo tardio, o seu currículo é elaborado com bases na manutenção da ordem vigente, deixa, portanto, de promover espaços de reflexão sobre as contradições sociais, ensina os valores burgueses e os defende como legítimos. Desta forma o ensino não pode ser considerado neutro, visto que ele serve os interesses do projeto capitalista, a saber, formar mão de obra qualificada, isto é, com habilidades e competências necessárias para atuação no mercado de trabalho.

A função social da escola, segundo Adorno, é de se opor a uma existência determinada pelo discurso vigente, de modo a promover constantemente um confronto crítico com a manutenção deste discurso, contribuindo, portanto, na construção de subjetividades com a razão e a sensibilidade emancipadas, de forma a não serem compatíveis com os ditames da condição social instaurada.

Opor-se a isto tudo que o mundo de hoje nos oferece e que, no presente momento, não admite vislumbrar qualquer outra possibilidade de resistência mais ampla, é competência da escola. É por essa razão que [...] é tão essencialmente importante que ela cumpra sua missão ${ }^{18}$.

A formação emancipatória voltada para a primazia da resistência resgata também o lugar social do sujeito, considerado enquanto finalidade e não como meio. Esta concepção de sujeito diferencia-se do capitalismo que homogeneíza e ao mesmo tempo anula o sujeito em conseqüência de uma visão utilitária que o torna coisificado em contrapartida do fim último: o interesse econômico. Portanto, a função política da educação comprometida com a emancipação, que prioriza provisoriamente o momento da resistência; é a de superar a adaptação da condição social imposta pela ideologia da semicultura, na medida em que esta educação está amparada em uma postura crítica diante de tudo que condiciona o ser à alienação.

\section{Referências}

ADORNO, Theodor W. Educação e Emancipação. Tradução: Wolfgang Leo Maar. Rio de Janeiro: Paz e Terra, 1995.190p.

Teoria da Semicultura. In: Educação e sociedade n. 56. Tradução Bruno Pucci, Cláudia B. M. de Abreu e Newton Ramos-de-Oliveira. 1996. p. 388-411..

. Conceito de Iluminismo. In: Os Pensadores. Textos escolhidos. Tradução: Luiz João Baraúna. São Paulo: Nova Cultural, 1999. p. 17-64

${ }^{18}$ ADORNO, Theodor W. Educação e Emancipação. Tradução: Wolfgang Leo Maar. Rio de Janeiro: Paz e Terra, 1995. p. 79.

\begin{tabular}{|c|c|c|c|c|c|}
\hline intuitio & $\begin{array}{c}\text { ISSN } \\
1983-4012\end{array}$ & Porto Alegre & Vol.8 $-\mathrm{N}^{\mathrm{o}} .1$ & $\begin{array}{c}\text { Junho } \\
2015\end{array}$ & p.64-74 \\
\hline
\end{tabular}


Educação e política em Theodor Adorno: para onde a educação deve conduzir?

DUARTE, Rodrigo Antônio de Paiva. Mímesis e racionalidade: a concepção de domínio da natureza em Theodor W. Adorno. São Paulo: Loyola, 1993.

MAAR, Wolfgang Leo. Educação Crítica, Formação Cultural e Emancipação Política na Escola de Frankfurt. In: PUCCI, Bruno (org.). Teoria Crítica e Educação: A questão da formação cultural na escola de Frankfurt. Petrópolis: Vozes, 1995. p. 59-82..

PUCCI, Bruno. Teoria Crítica e Educação. In: PUCCI, Bruno (org.). Teoria Crítica e Educação: a questão da formação cultural na escola de Frankfurt. Petrópolis: Vozes, 1995. p. 11-58.

. A dialética negativa enquanto metodologia de pesquisa em educação: atualidades. Revista Ecurriculum, São Paulo, v.8 n.1 Abril 2012.

"Anotações sobre $\begin{array}{ccc}\text { teoria e práxis educativa." Dispo } & \text { e }\end{array}$ ZUIN, Antônio Álvaro Soares. Seduções e Simulacros: considerações sobre a indústria cultural e os paradigmas da resistência e da reprodução em educação. In: PUCCI, Bruno (org.). Teoria Crítica e Educação: A questão da formação na escola de Frankfurt. Petrópolis: Vozes, 1995. p.151-176.

Recebido em: 26/08/2014

Aprovado para publicação em: 23/05/2015

\begin{tabular}{|c|c|c|c|c|c|}
\hline intuitio & $\begin{array}{c}\text { ISSN } \\
1983-4012\end{array}$ & Porto Alegre & Vol.8 $-\mathrm{N}^{\circ} .1$ & $\begin{array}{c}\text { Junho } \\
2015\end{array}$ & p.64-74 \\
\hline
\end{tabular}

